\title{
Students' Perception on Learning Unit Conversion Through a Smart Conversion Card Tool
}

\author{
Siti Nafisah Md Rashid ${ }^{1, *}$, Azlina Baha ${ }^{1}$, Dzeelfa Zainal Abidin ${ }^{2}$ \\ ${ }^{1}$ School of Physics and Material Science, Faculty of Applied Sciences, ${ }^{2}$ Academy of Language Studies \\ Universiti Teknologi MARA Cawangan Negeri Sembilan \\ Kuala Pilah, Malaysia \\ *nafisah@uitm.edu.my
}

\begin{abstract}
In the fundamental of Physics, the measurement of physical quantities is expressed in terms of units. However, most students have been having difficulties in understanding the correct method to perform unit conversion of any physical quantities. To tackle this problem, the use of flashcards namely Smart Conversion Card (SCC) tool was introduced in the teaching and learning process. This paper discusses the students' perception towards the effectiveness of using flashcards in Physics I (PHY430) course, in order to give them better understanding of the concept of unit conversion that need to be applied throughout the syllabus. The flashcards were distributed among students who enrolled in the PHY430 course during their first semester of study in the Bachelor's Degree (Hons) Computational Mathematics programme in UiTM Branch of Negeri Sembilan, Campus of Seremban. The effectiveness of using flashcards as a learning tool was demonstrated through scores obtained by the students' responses in the pre-test and post-test questions. Based on the results obtained, $84 \%$ of students managed to perform unit conversion after using the flashcards, and $70 \%$ of them improved their score in post-test questions.
\end{abstract}

Keywords—flashcards, unit conversion, learning tools, physics

\section{INTRODUCTION}

The measurement system was described as a communication tool for people to communicate in business, industry and everyday life [1]. In 1960, the International System of Units (SI) was adopted as a standardized measurement system to ease this communication. Basically, there are seven main units described in this system such as length, mass, time, temperature, electric current, luminous intensity and amount of substance.

At the university level, conversion unit is a basic topic learned in fields of study such as science, physics, chemistry, mathematics, engineering, economy, architecture to name a few. Usually, this topic is learned at the beginning of a particular course. In the Faculty of Applied Sciences, UiTM Branch of Negeri Sembilan, the topic of conversion unit is contained in the course syllabus of Physics for Pre-Science (PHY083), Fundamental Physics I (PHY130), Physics for NonMajor (PHY400) and Physics I (PHY430). These courses are enrolled by students from the pre-diploma, diploma and degree level. Students must be well-versed with this topic as it will be applied in further topics in the various programmes. Failing to do so will affect students' performance not only in the course but also in the program enrolled. Even though there are many digital converters available on the internet, students should be able to know the conversion techniques and perform it manually.

Generally, the two types of conversion units which are prefix and metric. In order to perform the prefix unit conversion, the conversion factor value such as Tera $\left(10^{12}\right)$, Giga $\left(10^{9}\right)$, micro $\left(10^{-6}\right)$ etc. are used. For the metric unit conversion, conversion factor value such as $1 \mathrm{inch}=2.54$ centimeter, 1 tonne $=1000$ kilogram etc. are used. In addition, unit conversion involves the conversion of two or three dimensions such as to convert inch ${ }^{3}$ into meter ${ }^{3}$.

Thus, an interactive learning tool called the Smart Conversion Card (SCC) tool was developed to obtain student participation and correctly execute the conversion unit. In addition, the SCC tool is also intended to assist the lecturer in the teaching and learning practices, as it will promote active learning in the classroom. By using this learning approach, students' visualization and conceptual understanding will be enhanced in performing unit conversion, especially in the Physics area.

\section{LITERATURE REVIEW}

Physics is usually taught in a conventional lecture-style format, in which the instructor provides the students with knowledge by talking to them. Visual simulation in a traditional classroom typically includes notes written by the instructor on a whiteboard or overhead projector and occasional demonstration of the phenomena [2]. This teaching style will create passive classroom participants in the future. In physics education, many students memorize equations and formulas, solve problems that require mathematical operations without understanding the subjects and concepts. Besides that, research also indicates that in order to be able to do physics and solve problems in physics, a good mathematical background is vital, as mathematics is a pre-requisite for the majority of 
physics courses [3]. Essential skills are described as a requirement at the university-level courses and include metric prefixes and conversions.

Several other reports also show that the students had difficulties and failed to convert metric units. It was found that students were more effective in converting units of length rather than the volume [4], as well as having trouble encountering prefixes such as Nano and Mega, since they could not rely on their memorized prefixes [5]. Thus, in order to address this problem, the integration of teaching resources and the use of teaching tools in teaching and learning is one of the solutions to enhance students' understanding of this topic and facilitate an active learning environment in the classroom. In this study, the "smart conversion cards" (SCC) which have the look and feel of flashcards were created and embedded in teaching unit conversion.

Using flashcards can be a very effective self-testing approach. Furthermore, it can help students develop their attention, attitudes, motivation, and visualization skills on the topics they find hard to understand. Flashcards are also part of spaced practice, and the repetition helps students to identify the right steps in the conversion of the metric unit.

\section{Methodology}

The participants for the study were selected based on purposive sampling. They consisted of 20 degree students in Computational Mathematics (CS247) at Universiti Teknologi MARA Negeri Sembilan, Seremban Campus, Malaysia. They have enrolled in Physics I (PHY430) course during their first semester of study. The study was conducted in a physics labarotary during the practical session by one of the researchers who taught this course at the Seremban campus. Steps in the study are as shown in Figure 1-4.

\section{A. Step 1: Screening of the Learner's Understanding in the Topic of Unit Conversion}

The class instructor taught the topic of unit conversion in class. A set of questions consisting of 10 questions that is related to the unit conversion topic was distributed among the students. They were given 30 minutes to prepare the answers and show their calculation method on a piece of paper. After that, the students submitted their work to be evaluated by the instructor.

\section{B. Step 2 : Development and Implementation of Teaching Tool}

The instructor introduced and demonstrated the method to perform unit conversion by using the flashcards, namely the SCC Tool to the students, as shown in Figure 1. The purpose of using this tool was to help students in visualizing and understanding the correct method to perform unit conversion. A set of SCC tool was provided to the students, which consists of flashcards, user guideline, set of numbers and units, scientific calculator, marker pen and display board. The game was played using the following steps
- The game requires students to work in pairs.

- The students need to read the question on the flashcard, as shown in Figure 2. Then, they have to pick the suitable numbers and units to be arranged on the display board in order to perform unit conversion, as shown in Figure 3 .

- The students will use a scientific calculator to perform the calculation, and then write the answers in the space provided on the display board.

- The students need to turn over the flashcard to check whether their method and answer are correct.

- The same steps can be used to solve other questions that was already printed on the flashcard.

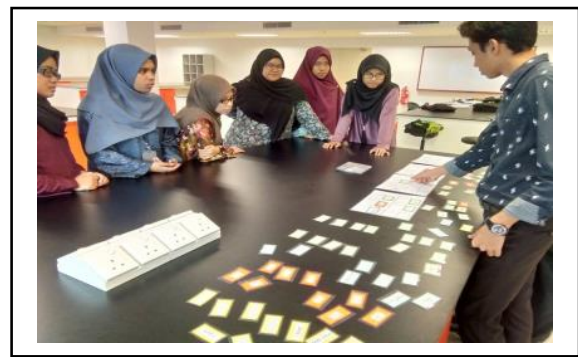

Fig. 1. Demonstration of using SCC tool to the students.

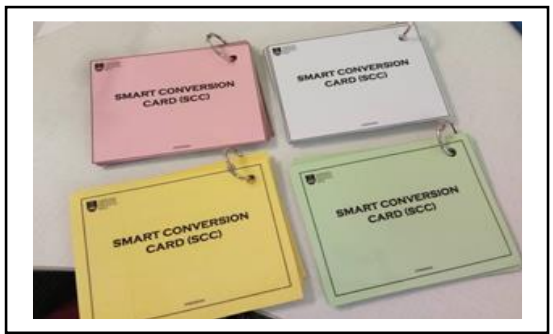

Fig. 2. Flashcards used in SCC tool.

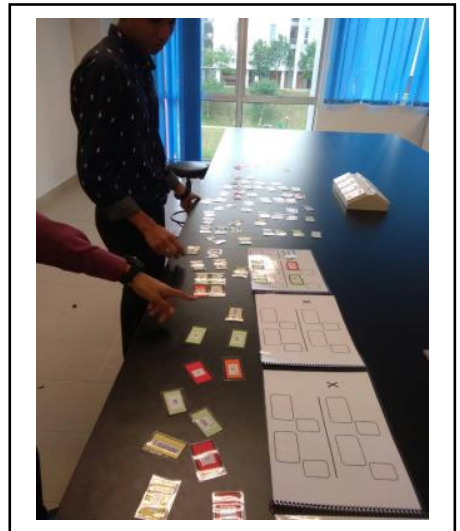

Fig. 3. Student needs to pick and arrange the numbers and units on a display board. 


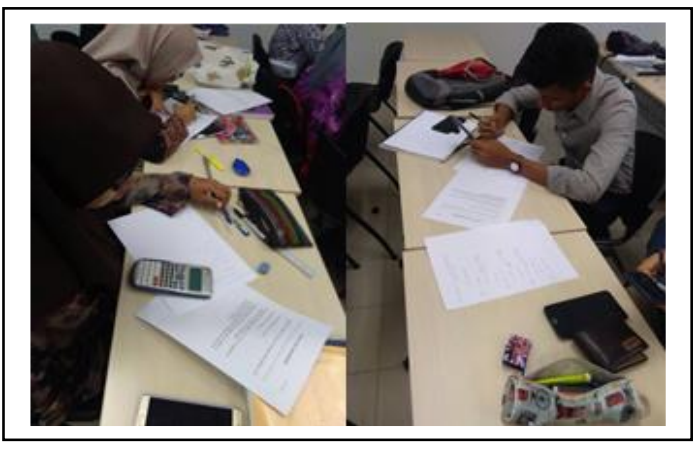

Fig. 4. Students show their method of performing unit conversion before and after using SCC tool.

\section{Step 3: Evaluation of Students' Performance}

After the students have finished playing the game using the SCC tool, a similar set of questions like the ones given earlier were distributed to them, as shown in Figure 4. They were required to answer the questions within 30 minutes and submit them to the instructor to be assessed. Besides that, there was a questionnaire prepared using the Google Form distributed to them through WhatsApp message. All items in this questionnaire were measured using the Likert scale showing '1-Strongly Disagree, 2-Disagree, 3-Neutral, 4-Agree, 5Strongly Agree'. The questionnaire contains statements that reflect the students' perceptions of using the SCC tool as an aid in teaching and learning activity.

\section{RESULTS AND DISCUSSION}

\section{A. Ease of Use of the SCC Tool}

Two items were developed to determine the abovementioned effect as shown in Table 1. Based on the responses given by the students, it was found that all scores from the two statements are above average with the highest mean value of 4.21. This indicates that the respondents agree with the statement that the SCC tool is easy to use and helps them to perform unit conversion in this course.

By integrating flashcards into the teaching and learning activities, students have been able to demonstrate the right calculation steps to solve unit conversion problems. Besides that, using flashcards has benefits as they are simple to make and can be used either individually or in groups [6].

TABLE I. Mean VAlue of the Perceived Use of SCC ToOL

\begin{tabular}{|c|c|c|}
\hline \multirow{2}{*}{ Factor } & \multicolumn{2}{|l|}{ Description } \\
\hline & Statement & Mean value \\
\hline \multirow{2}{*}{$\begin{array}{l}\text { Ease of } \\
\text { use }\end{array}$} & $\begin{array}{l}\text { I know how to demonstrate SCC } \\
\text { tool for a given situation. }\end{array}$ & 4.10 \\
\hline & $\begin{array}{l}\text { I am able to do unit conversion } \\
\text { by applying this SCC tool. }\end{array}$ & 4.21 \\
\hline
\end{tabular}

\section{B. Students' Cognitive Level}

Two items were developed to determine students' cognitive development towards the application of the SCC tool in teaching and learning activity. Based on the results in Table 2, it was found that all scores from the two statements are above average with the mean value of 4.21. This shows that the respondents agree that the implementation of the SCC tool in teaching and learning is very beneficial to them, as it enhances their visualization skills and improves their conceptual understanding in performing unit conversion.

This study has shown that the flashcards are designed to enable retrieval practice. This occurs as students flip through the prompts on one side of the flashcard and attempt to recall the answer recorded on the back of the card. This can only be done if the students practice using flashcard several times, as they develop their memory skills. It is found that the amount of practice and the timing of practice are the two crucial factors that affect the students' skills to perform unit conversion [7]. Many studies have found that retrieval practice increases the retention of information [8].

TABLE II. Mean Value of Students' Cognitive Development

\begin{tabular}{|c|c|c|}
\hline \multirow{2}{*}{ Factor } & \multicolumn{2}{|l|}{ Description } \\
\hline & Statement & Mean value \\
\hline \multirow{2}{*}{$\begin{array}{l}\text { Students' } \\
\text { Cognitive } \\
\text { Development }\end{array}$} & $\begin{array}{l}\text { SCC tool has increased my } \\
\text { understanding to perform unit } \\
\text { conversion. }\end{array}$ & 4.21 \\
\hline & $\begin{array}{l}\text { SCC tool has improved my } \\
\text { visualization in unit conversion } \\
\text { by using unit cancellation } \\
\text { method. }\end{array}$ & 4.21 \\
\hline
\end{tabular}

\section{Effectiveness of Using SCC Tool}

The effectiveness of SCC tool was evaluated through the scores obtained by the students in pre-test and post-test questions. Based on the graph shown in Figure 5, 70\% of the students improved their post-test marks and managed to perform unit conversion after being introduced to the SCC tool. However, $25 \%$ of the students remain the same and only $5 \%$ got lower marks.

Flashcards have previously been tested for their effectiveness in learning vocabulary [9], however, in light of our findings, flashcards also can be utilized as a useful activity, allowing students to practice converting metric units in physics courses. In addition, it provides solution for them to study independently as well as inspire them to excel over the course of the entire semester. 


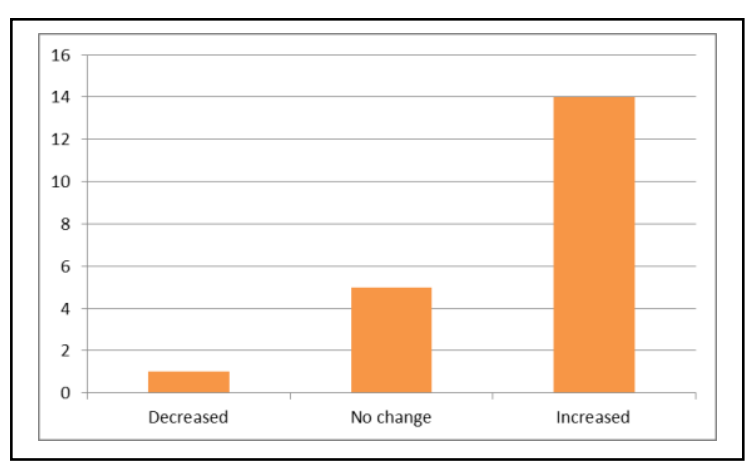

Fig. 5. Comparison of scores obtained by the students in pre-test and posttest questions.

\section{CONCLUSION}

In conclusion, the SCC flashcards is a significant learning tool as it facilitates students in performing unit conversion in the Physics course. The SCC tool is helpful in the learning process, as it develops students' visualization and conceptual understanding of this topic. Besides that, it also encourages the educators to create new teaching aid material to be implemented in the classroom, to promote students' active learning through participation and involvement.

\section{ACKNOWLEDGMENT}

The authors would like to thank the Bachelor's Degree (Hons) students of Computational Mathematics at UiTM
Branch of Negeri Sembilan, Seremban Campus for their time, support and feedback on all the conducted activities.

\section{REFERENCES}

[1] E.O. Dincer and A. Osmanoglu, "Dealing with Metric Unit Conversion: An Examination of Prospective Science Teachers' Knowledge of and Difficulties with Conversion”, Science Education International, vol. 29, no. 3, pp. 174-182, 2018.

[2] T. Larkin-Hein, "New Methods for Teaching Introductory Physics to Non-Majors," ASEE Annual Conference Proceedings, pp. 4433-43, 2000.

[3] D.H. Nguyen, Facilitating Students' Application of the Integral and the Area Under the Curve Concepts in Physics Problems. Doctoral dissertation, Kansas State University, 2011.

[4] J. Gilman, Have you Met Ric? Student Misconceptions of Metric Conversions and the Difficulties Behind Metric Unit Estimation. Doctoral dissertation, State University of New York at Fredonia, 2013.

[5] J.E. Hallagan, "Preservice mathematics teachers' solutions to problems: Conversions within the metric system," Systemics, Cybernetics and Informatics, vol. 11, no. 7, pp. 15-20, 2013.

[6] J. Klaiss, "Engaging Mathematics Games vs Flashcards Improving the Mathematics Fact Fluency of First Grade Student," 2017.

[7] K.T. Wissman, K.A. Rawson, and M.A. Pyc, "How and when do students use flashcards?" Memory, vol. 20, no. 6, pp. 568-579, 2012.

[8] C. Lin, M.A. McDaniel, and T. Miyatsu, "Effects of flashcards on learning authentic materials: The role of detailed versus conceptual flashcards and individual differences in structure-building ability," Journal of applied research in memory and cognition, vol. 7, no. 4, pp. 529-539, 2018.

[9] J. Serfaty and R. Serrano, "Examining the potential of digital flashcards to facilitate independent grammar learning," System, vol. 94, p. 102342, 2020. 